09;15

\title{
Определение коэффициента теплоотдачи твердотельных объектов методом лазерной фототермической ИК-радиометрии
}

\author{
(C) С.Е. Александров, Г.А. Гаврилов, А.А. Капралов, \\ К.Л. Муратиков Ф, Г.Ю. Сотникова
}

Физико-технический институт им. А.Ф. Иофффе РАН, Санкт-Петербург ๑ E-mail: klm.holo@mail.ioffe.ru

\section{Поступило в Редакцию 31 марта 2017 г.}

Предложен простой способ определения коэффициента теплоотдачи твердотельных объектов, основанный на прямых измерениях динамики температуры поверхности образца с использованием фотодиодов среднего ИК-диапазона спектра, работающих без принудительного охлаждения, при тепловом воздействии на объект излучением лазера с заданным законом изменения мощности во времени.

DOI: $10.21883 /$ PJTF.2017.14.44825.16805

Фототермические методы на протяжении многих лет активно используются для определения тепловых [1,2] и оптических [3] параметров материалов, изучения влияния структурных и контактных неоднородностей на процессы теплопереноса [4-7]. Их важным достоинством являются бесконтактность, высокое пространственное и временно́е разрешение, возможность проведения измерений на незначительных объемах вещества. Последнее обстоятельство часто делает использование указанных методов единственно возможным для определения теплофизических свойств объектов с субмикронными размерами [8].

Среди фототермических методов важное положение занимает лазерная фототермическая радиометрия (ФТР) [9,10]. ФТР основывается на регистрации нестационарного ИК-излучения, испускаемого объектом, при его облучении модулированным во времени лазерным излучением. Для регистрации ИК-излучения при ФТР-экспериментах в настоящее время апробированы фотоприемники $\mathrm{HgCdTe}, \mathrm{InSb}$, охлаждаемые жид- 
ким азотом. При этом регистрация ИК-излучения осуществляется в достаточно широком спектральном диапазоне. Например, в случае фотоприемников $\mathrm{HgCdTe}$ серий KMPV и KLD (Kolmar Technologies, Inc.) используется излучение в диапазоне от 2 до $12 \mu \mathrm{m}$ или от 2 до $9 \mu \mathrm{m}$. Использование излучения широкого спектрального диапазона для формирования сигнала имеет как достоинства, так и недостатки. К достоинствам указанных детекторов следует отнести их высокую чувствительность к тепловому излучению, а к недостаткам - необходимость охлаждения до температуры жидкого азота и значительную методическую погрешность измерений.

Одним из важнейших параметров при изучении теплофизических процессов в твердотельных объектах является коэффициент теплоотдачи [11]. Он может являться существенным источником погрешности в теплофизических экспериментах. К сожалению, коэффициент теплоотдачи зависит от конкретных условий проведения эксперимента и является экспериментально сложно контролируемым параметром, часто требующим проведения специальных исследований [12]. В данной работе представлен простой и эффективный метод определения коэффициента теплоотдачи твердотельных объектов методом ФТР, основанный на прямых измерениях абсолютной температуры поверхности тестового образца спектрально-селективными иммерсионными фотодиодами (ФД) среднего ИК-диапазона спектра $(2-5 \mu \mathrm{m})$, работающими без принудительного охлаждения [13]. Высокая детектирующая способность $\left(D^{*} \sim 2 \cdot 10^{10}-10^{11} \mathrm{~cm} \cdot \sqrt{ } \mathrm{Hz} / \mathrm{W}\right)$, быстродействие (меньше $\left.20 \mathrm{~ns}\right)$ и конструктивные особенности ФД были использованы для создания на их основе высокочувствительных неохлаждаемых пирометрических сенсоров для бесконтактного измерения температуры. Важным достоинством указанных сенсоров является их полная нечувствительность к излучению с $\lambda \leq 1 \mu \mathrm{m}[14]$, которая обеспечивает возможность использования разнообразных лазеров возбуждающего излучения.

В рамках данной работы была поставлена задача измерения коэффициента теплоотдачи $H$, который в ходе теплофизических экспериментов трудно контролируется. С этой целью было предложено производить прямые измерения динамики температуры поверхности тестового образца материала с известными физическими параметрами при тепловом воздействии лазерным излучением с заданным законом изменения мощности во времени. В работе осуществлялась равномерная засветка лицевой поверхности образцов лазерным излучением. Отвод тепла от

Письма в ЖТФ, 2017, том 43, вып. 14 
их торцов не играл существенной роли, так как их суммарная площадь была значительно меньше площади лицевых поверхностей. В этих условиях распределение температуры внутри образца можно найти с помощью одномерного уравнения теплопроводности

$$
\rho C \frac{\partial T}{\partial t}=K \frac{\partial^{2} T}{\partial x^{2}}+Q(x, t),
$$

где $\rho$ - плотность материала образца, $C-$ его удельная теплоемкость, $K$ - теплопроводность, $Q(x, t)=\alpha(1-R) I_{0} e^{-\alpha x} f(t)-$ плотность мощности теплового источника, генерируемого лазерным излучением, $\alpha$ - коэффициент поглощения излучения поверхностью образца, $I_{0}-$ интенсивность излучения лазера, $R$ - коэффициент отражения света поверхностью образца, $f(t)$ - функция, описывающая временну́ю зависимость теплового воздействия.

Для решения уравнения (1) необходимо задать граничные условия. Для образцов, лицевые поверхности которых расположены при $x=0$ и $x=L$ с учетом теплоотвода в окружающую среду, эти условия имеют вид

$$
\left.K \frac{\partial T}{\partial x}\right|_{x=0, L}=\left.H\left(T-T_{0}\right)\right|_{x=0, L},
$$

где $H-$ коэффициент теплоотдачи, $T_{0}-$ температура окружающей среды.

При этом нетрудно найти зависимость температуры поверхности образца $T_{s}$ от времени, проинтегрировав уравнение (1) по его объему. С использованием теоремы Гаусса и с учетом граничных условий (2) эту зависимость получим в виде

$$
T_{s}(t)=\frac{I_{0}}{\rho C L} \int_{t_{1}}^{t} d t^{\prime} e^{-\frac{2 H}{\rho C L}\left(t-t^{\prime}\right)} f\left(t^{\prime}\right)+T_{0},
$$

где $t_{1}$ - время начала лазерного воздействия.

При выводе соотношения (3) учитывалось, что для исследуемых образцов выполняется неравенство $K \gg H L$ и в момент измерений температуры лицевой и тыльной поверхностей образцов результаты имеют достаточно близкие значения. Такая ситуация реализуется при длительностях засветки $\tau$, удовлетворяющей неравенству $\sqrt{ }(\kappa \tau) \ll L$, где $\kappa$ - коэффициент температуропроводности материала.

Письма в ЖТФ, 2017, том 43, вып. 14 
В эксперименте исследовались тестовые образцы чистых металлов (Ti и $\mathrm{Ni}$ ), значения $\rho, C$ и $K$ для которых хорошо известны, но при этом существенно отличаются. Образцы представляли собой диски одинаковой площади $103 \mathrm{~mm}^{2}$, но различной толщины: $L=400 \mu \mathrm{m}$ для Тi-образца и $L=800 \mu \mathrm{m}$ для Ni-образца. Для выбранных образцов значения $K / L$ составляют $55 \cdot 10^{3} \mathrm{~W} /\left(\mathrm{m}^{2} \cdot \mathrm{K}\right)$ для Ті-образца и $112 \cdot 10^{3} \mathrm{~W} /\left(\mathrm{m}^{2} \cdot \mathrm{K}\right)$ для Ni-образца, что обеспечивает выполнение условия $K \gg H L$, использованное при выводе уравнения (3), для значений $H \leq\left(10^{2}-10^{3}\right) \mathrm{W} /\left(\mathrm{m}^{2} \cdot \mathrm{K}\right)$.

Нагрев образцов осуществлялся излучением мощного полупроводникового лазера с длиной волны излучения $\lambda=980 \mathrm{~nm}$ и регулируемой мощностью излучения $0.1-1 \mathrm{~W}$. При этом $f(t)$ задавалась в виде единичного прямоугольного импульса. В этом случае решение уравнения (3) имеет вид

$$
\begin{aligned}
& T_{s}(t)=\frac{I_{0}}{2 H}\left(1-e^{-\frac{2 H}{\rho C L}\left(t-t_{1}\right)}\right)+T_{0}, \text { при } t_{1}<t \leq t_{2}, \\
& T_{s}(t)=T_{s}\left(t_{2}\right) e^{-\frac{2 H}{\rho C L}\left(t-t_{2}\right)}, \text { при } t>t_{2},
\end{aligned}
$$

где $t_{1}-$ время начала лазерного воздействия, $t_{2}-$ время его окончания.

Таким образом, обеспечив измерения температуры образцов с известными значениями $\rho, C$ и $L$ и аппроксимировав полученные кривые функциями вида (4), можно определить важную для теплофизических измерений константу $H$. Принято считать, что коэффициент теплоотдачи не зависит от материала образца, но зависит от способа и качества обработки его поверхности. При этом минимальное значение коэффициента теплоотдачи достигается для гладких поверхностей. В условиях свободной конвекции воздуха оно составляет $5.6 \mathrm{~W} /\left(\mathrm{m}^{2} \cdot \mathrm{K}\right)[15]$.

Тестовые образцы помещались в плоскую кювету с сапфировыми окнами, что обеспечивало возможность бесконтактного пирометрического контроля температуры обеих поверхностей образца. Для увеличения коэффициента поглощения лазерного излучения и излучательной способности образцов их поверхности покрывались тонким слоем поглощающего материала. Для контроля температуры поверхностей использовались ФД типа PD42SrNB, чувствительные в области $\Delta \lambda=3.4-4.4 \mu \mathrm{m}$ (по уровню 0.5) [13]. ФД использовался без дополнительных оптических элементов. Электронное обрамление ФД обеспечивало детектирование теплового излучения в полосе $1 \mathrm{kHz}$ (быстродействие $1 \mathrm{~ms}$ ),

Письма в ЖТФ, 2017, том 43, вып. 14 

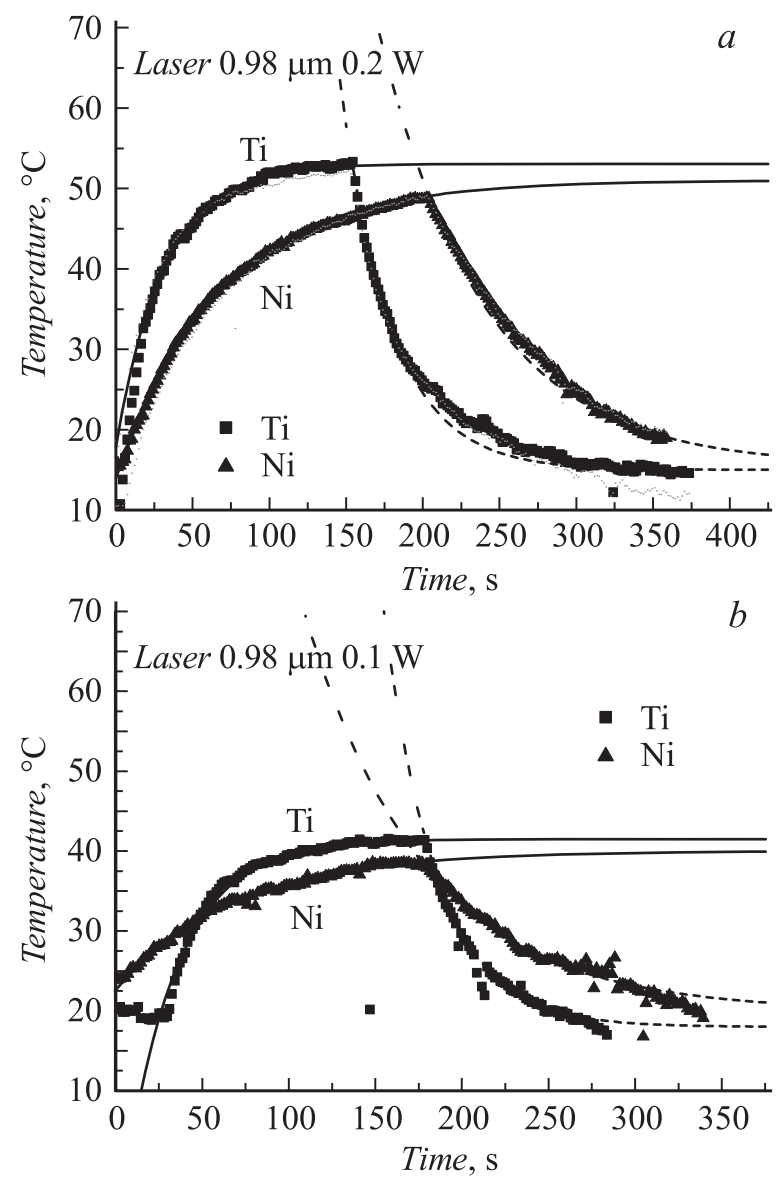

Экспериментальные значения температуры поверхности образцов Тi и $\mathrm{Ni}$ при их нагреве постоянным излучением лазера мощностью $0.1 \mathrm{~W}(a)$ и $0.2 \mathrm{~W}(b)$ и остывании после выключения лазера. Сплошными (нагревание) и пунктирными (остывание) линиями на графиках представлены решения уравнения (3) для известных значений $\rho, C$ и $L$ указанных образцов и рассчитанного из графиков значения $H=19.8 \mathrm{~W} /\left(\mathrm{m}^{2} \cdot \mathrm{K}\right)$. 
оцифровку, передачу на ПК, on-line расчет и вывод на экран монитора значений температуры поверхностей исследуемого образца в диапазоне от $10^{\circ} \mathrm{C}$ с точностью $0.1^{\circ} \mathrm{C}$. На рисунке в качестве примера представлены графики изменения температуры передней (облучаемой лазером) поверхности образцов Li и $\mathrm{Ni}$ при воздействии на них лазера. Для удобства представления данные по температуре, регистрируемые с быстродействием $1 \mathrm{~ms}$, на графиках прорежены и имеют временно́е разрешение $1.5 \mathrm{~s}$. Полученные экспериментально температурные кривые хорошо аппроксимируются функциями вида (4) и позволяют рассчитать коэффициент теплоотдачи в каждом эксперименте. В результате расчетов были получены значения коэффициента теплоотдачи для Тi-образца, равные $19.6 \mathrm{~W} /\left(\mathrm{m}^{2} \cdot \mathrm{K}\right)$ при мощности излучения $0.2 \mathrm{~W}$ (по показаниям индикатора драйвера лазера) и $22.4 \mathrm{~W} /\left(\mathrm{m}^{2} \cdot \mathrm{K}\right)$ при мощности излучения $0.1 \mathrm{~W}$. Для Ni-образца аналогичные измерения дали значения 18 и $20 \mathrm{~W} /\left(\mathrm{m}^{2} \cdot \mathrm{K}\right)$ при мощности излучения 0.2 и $0.1 \mathrm{~W}$ соответственно. Полученные значения хорошо согласуются с данными $\left(5.6 \leq H \leq 25 \mathrm{~W} /\left(\mathrm{m}^{2} \cdot \mathrm{K}\right)\right)$, приводимыми для условий свободной конвекции воздуха. Разброс значений коэффициента теплоотдачи можно объяснить возможными различиями в обработке поверхности образцов и отклонениями показаний индикатора мощности драйвера лазера от ее истинных значений (точность установки мощности излучения для использованного полупроводникового лазера составляла $\pm 10 \%$ ).

Таким образом, полученные результаты демонстрируют возможность определения коэффициента теплоотдачи простым и эффективным ФТР-методом при проведении теплофизических экспериментов на твердотельных образцах. Показано, что разработанные ФД пирометрические сенсоры среднего ИК-диапазона способны обеспечивать проведение теплофизических измерений новых материалов в широком диапазоне температур, начиная с комнатной, без принудительного охлаждения фотоприемника.

\section{Список литературы}

[1] Mingolo N.A., Martinez O.E. // J. Appl. Phys. 2012. V. 111. P. 12352 (1-7).

[2] Kim H.J., Kim J.H., Jeon P.S., Yoo J. // J. Mech. Sci. Technol. 2009. V. 23. P. $2514-2520$

Письма в ЖТФ, 2017, том 43, вып. 14 
[3] Pawlak M., Chirtoc M., Horny N., Pelzl J. // J. Appl. Phys. 2016. V. 119. P. 125108 (1-11).

[4] Escola F.Z., Kunik D., Martinez O.E., Mingolo N. // Procedia Mater. Sci. 2015. V. 8. P. $665-673$.

[5] Глазов А.Л., Козлов В.А., Муратиков К.Л. // Письма в ЖТФ. 2011. Т. 37. B. 24. C. $16-25$.

[6] Глазов А.Л., Калиновский В.С., Лисицина Ю.Г. и др. // Письма в ЖТФ. 2011. T. 37. В. 14. C. $60-67$.

[7] Глазов А.Л., Калиновский В.С., Контрош Е.В., Муратиков К.Л. // Письма в ЖТФ. 2016. Т. 42. В. 11. С. 33-40.

[8] Gaskins J.T., Yadav A.K., Duda J.C. et al. // Appl. Phys. Lett. 2015. V. 106. P. 093114 (1-5).

[9] Mandelis A., Batista J., Shaughnessy D. // Phys. Rev. B. 2003. V. 67. P. 205208 (1-18).

[10] Fuente R., Apinaniz E., Mendioroz A., Salazar A. // J. Appl. Phys. 2011. V. 110. P. 033515 (1-9).

[11] Пикулев А.А. // ЖТФ. 2003. Т. 73. В. 6. С. 32-35.

[12] Fernandez-Siera J., Uhia F.J., Sieres J., Campo A. // Appl. Thermal Eng. 2007. V. 27. P. 2745-2757.

[13] $w w w$.ioffeled.com

[14] Александров С.Е., Гаврилов Г.А., Сотникова Г.Ю., Тер-Мартиросян А.Л. // ФТП. 2014. Т. 48. В. 1. С. $135-141$.

[15] Кухлинг Х. Справочник по физике. М.: Мир, 1982. 520 с. 